\title{
High Efficiency Release Targets for Use at ISOL Facilities: Computational Design
}

\author{
Y. Liu and G. D. Alton \\ Physics Division, Oak Ridge National Laboratory* \\ P. O. Box 2008, Oak Ridge, TN $37831-6368$
}

\begin{abstract}
This report describes efforts made at the Oak Ridge National Laboratory to design highefficiency-release targets that simultaneously incorporate the short diffusion lengths, high permeabilities, controllable temperatures, and heat-removal properties required for the generation of useful radioactive ion beam (RIB) intensities for nuclear physics and astrophysics research using the isotope separation on-line (ISOL) technique. Short diffusion lengths are achieved either by using thin fibrous target materials or by coating thin layers of selected target material onto low-density carbon fibers such as reticulated-vitreous-carbon fiber (RVCF) or carbon-bonded-carbon fiber (CBCF) to form highly permeable composite target matrices. Computational studies that simulate the generation and removal of primary beam deposited heat from target materials have been conducted to optimize the design of target/heat-sink systems for generating RIBs. The results derived from diffusion release-rate simulation studies for selected targets and thermal analyses of temperature distributions within a prototype target/heat-sink system subjected to primary ion beam irradiation will be presented in this report.
\end{abstract}

PACS:

Corresponding author: $\quad$ Yuan Liu

Oak Ridge National Laboratory

P. O. Box 2008

Bldg. 6000, MS-6368

Oak Ridge, TN 37831-6368

Telephone: $423-574-4761$

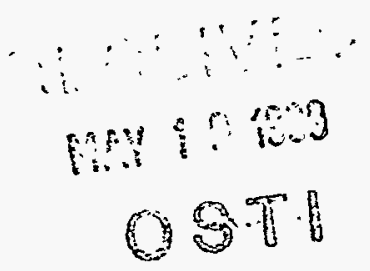

FAX: 423-574-1268 \footnotetext{
Department of Energy.

- Managed by Lockheed Martin Energy Research Corp. under contract DE-AC05-960R22464 with the U.S. 


\section{DISCLAIMER}

Portions of this document may be illegible in electronic image products. Images are produced from the best available original document. 


\title{
High Efficiency Release Targets for Use at ISOL Facilities: Computational Design
}

\author{
Y. Liu and G. D. Alton \\ Physics Division, Oak Ridge National Laboratory \\ P. O. Box 2008, Oak Ridge, TN 37831-6368
}

This report describes efforts made at the Oak Ridge National Laboratory to design highefficiency-release targets that simultaneously incorporate the short diffusion lengths, high permeabilities, controllable temperatures, and heat-removal properties required for the generation of useful radioactive ion beam (RIB) intensities for nuclear physics and astrophysics research using the isotope separation on-line (ISOL) technique. Short diffusion lengths are achieved either by using thin fibrous target materials or by coating thin layers of selected target material onto low-density carbon fibers such as reticulated-vitreous-carbon fiber (RVCF) or carbon-bonded-carbon fiber ( $\mathrm{CBCF}$ ) to form highly permeable composite target matrices. Computational studies that simulate the generation and removal of primary beam deposited heat from target materials have been conducted to optimize the design of target/heat-sink systems for generating RIBs. The results derived from diffusion release-rate simulation studies for selected targets and thermal analyses of temperature distributions within a prototype target/heat-sink system subjected to primary ion beam irradiation will be presented in this report. 


\section{INTRODUCTION}

The Holifield Radioactive Ion Beam Facility (HRIBF) at the Oak Ridge National Laboratory is designed to provide energetic radioactive ion beams (RIBs) for nuclear physics and astrophysics research. It uses the well-known on-line isotope separator (ISOL) technique in which radioactive nuclei are produced by fusion- or fission-type nuclear reactions in target materials by high-energy proton, deuteron, or He ion beams from the Oak Ridge Isochronous Cyclotron (ORIC). The generation of radioactive ion beams (RIBs) involves a multi-step process: the nuclear reaction products must diffuse to the surface of the target material, evaporate from the surface, and effusively flow to the ion source where a fraction of the species of interest are ionized, extracted from the source, and mass analyzed prior to postacceleration. The principal means whereby short-lived radioactive species are lost between initial formation and utilization are associated with the diffusion and surface adsorption processes where the hold-up times are long with respect to the life-time of the species of interest. Thus, successful RIB generation requires careful consideration of the physical, chemical, and metallurgical properties of the target material and thoughtful design of highly permeable target-matrix systems with short diffusion lengths and controllable target temperatures. Efforts are underway at the HRIBF to develop fast release targets with controllable temperatures for optimum production and generation of RIBs for use in the astrophysics and nuclear structure physics research programs [1]. In this report, we briefly review our computational efforts to address a 
number of important technical issues in the development of high efficiency release targets, including selecting appropriate target materials that form volatile reaction products, developing highly permeable solid-state refractory targets that are compatible with fast and efficient diffusion release of the candidate RIB species, and designing efficient heat removal target/heatsink systems to achieve the operation temperature that assures the fastest diffusion release from the target without compromising the ionization efficiency of the source.

\section{TARGET MATERIAL SELECTION}

The most challenging task related to the efficient generation of RIBs using the ISOL technique is the selection of the most appropriate target material that will efficiently and selectively release minute quantities of the short lived radioactive species in the presence of bulk quantities of the target material itself. Target material selection begins by considering the physical, chemical, and thermodynamic properties of the target material in relation to those of the product species. The primary problem lies in the lack of sufficiently refractory target materials that can be heated to the elevated temperatures necessary for fast release of the product radioactive species without vaporization or sublimation of the target material itself. The maximum target temperature is also limited by the vapor pressure requirement of the ion source. The choice of target material is further restricted by the requirement that the radioactive species must be easily diffused from the target and volatile in either elemental or compound form for 
fast transportation to the ion source. This requires the species itself not be refractory and does not form refractory compounds within the target.

Several computer codes, including ThermoCalc, HSC, and ChemSage, have been used to study the chemical reaction and thermodynamic properties of different target materials and the released products. New target concepts that are presently under development at HRIBF include the choice of low-density target matrices, such as refractory metal oxide fibers, carbon-bondedcarbon fiber (CBCF), and reticulated-vitreous-carbon fiber (RVCF). These fibrous materials are refractory and highly porous (density typically 0.06 to $0.12 \mathrm{~g} / \mathrm{cm}^{3}$ ). Figure 1 shows the vapor pressures, calculated with ThermoCalc, of several metal oxides, $\mathrm{Al}_{2} \mathrm{O}_{3}, \mathrm{ZrO}_{2}, \mathrm{HfO}_{2}$, and $\mathrm{Y}_{2} \mathrm{O}_{3}$, that are chosen as candidate target materials for the production of $\mathrm{F}$ isotopes for the astrophysics research program at HRIBF. The maximum operating temperature of these metal oxide targets is set by the target vapor pressure that must be below $2 \times 10^{-4}$ Torr for the CERN-type electronbeam-plasma ion source presently used at the $\mathrm{HRIBF}$ [2]. Thin $\mathrm{Al}_{2} \mathrm{O}_{3}$ fibrous targets have been successfully used during on-line production and release of ${ }^{17} \mathrm{~F}$ and ${ }^{18} \mathrm{~F}[3]$. The maximum operating temperature of the $\mathrm{Al}_{2} \mathrm{O}_{3}$ fibrous target was less than $1600^{\circ} \mathrm{C}$, limited by the target vapor pressure. Figure 1 shows that the target can be operated at much higher temperatures with $\mathrm{ZrO}_{2}$ and $\mathrm{HfO}_{2}$ materials $\left(2100^{\circ} \mathrm{C}\right.$ to $\left.2300^{\circ} \mathrm{C}\right)$, which, in turn, allow faster and much more efficient release of the short-lived ${ }^{17} \mathrm{~F}$ isotopes. Very recently, $\mathrm{HfO}_{2}$ fibrous targets have successfully provided ${ }^{17} \mathrm{~F}$ beams of sufficient intensities for the nuclear astrophysics research 
program at the HRIBF [4]. The first on-line test of $\mathrm{ZrO}_{2}$ fibrous target using the UNISOR facility demonstrated the capability of $10^{7} \mathrm{p} / \mathrm{s} / \mu \mathrm{A}{ }^{17} \mathrm{~F}$ yields in combination with the kinetic ejection negative ion source developed at the HRIBF [5]. Many other refractory materials such as the metal-carbides are under consideration for RIB applications. Low-density CBCF and RVCF are used as the plating matrix for the target material and the thermal transport conduit for heat removal from the target material. Very thin layers of selected target materials, for example, $\mathrm{Ni}, \mathrm{SiC}$, and $\mathrm{UC}_{2}$, have been uniformly deposited onto $\mathrm{RVCF}$ and $\mathrm{CBCF}$ to form composite target matrices using either electroplating (EP) or chemical vapor deposition (CVD) methods [6]. On-line release yields of a variety of radioactive species from $\mathrm{UC}_{2} / \mathrm{RVCF}$ composite targets have been recently measured at the UNISOR facility.

\section{PROTOTYPE TARGET/HEAT-SINK SYSTEM}

Control and maintenance of the target temperature at a desired value is very important for optimizing the production of RIBs. When low-intensity primary ion beams are used, the target must be externally heated to the desired operating temperatures because internal beam heating is not sufficient. For radioactive species that are less efficiently available, intense primary ion beams are desired to increase the RIB yields and the internal beam heating may raise the target temperature higher than the appropriate operating temperature; therefore, the target needs to be cooled. In particular, cooling is imperative for the low-density targets due to the fact that these 
highly permeable fibrous materials have low thermal conductivities. A prototype target/heatsink system now under design to provide heating and cooling for our low-density targets is displayed in Fig. 2. The primary beam, which produces the radioactive species, passes through a thin window and deposits energy in the target material during the slowing down process. The length of the target material is chosen so that the beam exits the target with $\sim 4 \mathrm{MeV}$ energy and comes to rest in a C-beam stop that is connected to a $\mathrm{Cu}$ heat sink that is directly cooled with water. The target material reservoir can be resistively heated when necessary to obtain the desired target temperatures.

\section{THERMAL ANALYSIS}

Computational studies are under way to optimize the design of the target/heat-sink system. The design objectives are to provide effective means for removal of beam-deposited heat from the target material at controlled rates so that, as high as practical, primary beam intensities can be used to produce the species of interest. Several computer codes have been used to simulate heat generation, heat transfer, and to estimate equilibrium temperature distributions in the target/heatsink system. Heat deposited in the target material by the primary ion beam was calculated by the use of the Monte Carlo code, Stopping and Range of Ions in Matter (SRIM) [7]. SRIM provides an efficient and fast method for quantitative evaluation of how ions lose their energy to the solid and the final distribution of the ions after they come to rest in the solid. SRIM accounts for all kinetic energy loss phenomena while slowing down in complex multi-layered 
targets made of elemental or compound materials; these phenomena include: target damage, sputtering, ionization, and phonon production. The beam-heating profile generated from SRIM results was used as the heat-generation load in the thermal analyses using the finite element code ANSYS [8].

The most challenging issue in designing the target/heat-sink system is to provide effective means to remove beam deposited heat from the low-density target matrix. This is due to the fact that the fibrous metal oxide materials have intrinsically poor thermal conductivity. Computational studies have been conducted to calculate the heat transport and temperature distributions in several targets designed for use at the HRIBF. These targets include: fibrous $\mathrm{Al}_{2} \mathrm{O}_{3}$ for ${ }^{17} \mathrm{~F}$ production using low-energy deuteron beams, Ni coated $\mathrm{RVCF}$ for ${ }^{58} \mathrm{Cu}$ production using low energy protons, and $\mathrm{UC}_{2}$ coated $\mathrm{RVCF}$ composite targets for production of fission products with $1 \mathrm{GeV}$ protons. In case of fibrous $\mathrm{Al}_{2} \mathrm{O}_{3}$ target, the operating target temperature is set by the vapor pressure limitation of the ion source system $\left(\sim 1650^{\circ} \mathrm{C}\right)$. For a $2.5-\mathrm{cm}$ long fibrous $\mathrm{Al}_{2} \mathrm{O}_{3}$ target irradiated by $20-\mathrm{MeV}$ deuteron beams of $8-\mathrm{mm}$ diameter, this limiting temperature is already reached at less than $45 \mathrm{~W}$ of deuteron beam power, if no cooling means is provided. The energy of the ion beam was chosen for the production of ${ }^{17} \mathrm{~F}$ isotopes via the nuclear reaction ${ }^{16} \mathrm{O}(\mathrm{d}, \mathrm{n}){ }^{17} \mathrm{~F}$. Several cooling approaches have been studied. Partially coating the $\mathrm{Al}_{2} \mathrm{O}_{3}$ matrix with a thin layer of Ir has shown to be an effective means for removal of heat from the target. Figure 3 shows the axial temperature distributions versus beam power in a 2.5- 
$\mathrm{cm}$ long $\mathrm{Al}_{2} \mathrm{O}_{3}$ target after adding a $25-\mu \mathrm{m}$ thick Ir foil spiral rolled between $1.5-\mathrm{mm}$ thickness layers of the $\mathrm{Al}_{2} \mathrm{O}_{3}$ fibrous matrix; the Ir foil longitudinally connects the target material to the cold $C$ beam stop. The maximum deuteron beam power can be increased to near $70 \mathrm{~W}$. As noted in Fig. 3, the axial temperature distribution within the target is largely un-uniform. To solve this problem, another approach recently studied is to bond the $\mathrm{Al}_{2} \mathrm{O}_{3}$ matrices to $0.05-\mathrm{mm}$ thick, $86 \%$ porous Mo mesh disks that are radially connected to the Ta target holder. This approach has shown to be more effective since the heat-removal path is shorter in the radial direction than in the longitudinal direction and resulted in more uniform temperature distribution within the target. Figure 4 presents the maximum $\mathrm{Al}_{2} \mathrm{O}_{3}$ target temperature vs. deuteron beam power without cooling means and with radial cooling by the use of 8 Mo mesh disks, respectively. For the low-density, highly porous targets, a simple approach, if practically possible, to handle more ion beam intensity is to increase the ion beam diameter. The effect of increase beam diameter is also shown in Fig. 4.

An interesting result, derived from our thermal analyses, is that radiative-heat transfer is more effective than conduction even at temperatures less than $1600^{\circ} \mathrm{C}$ for low thermal conductivity fibrous target materials, such as $\mathrm{Al}_{2} \mathrm{O}_{3}$. Further studies are needed to explore radiative-cooling effects. The beam heating results in a non-uniform temperature distribution profile, both radially and axially. It is desirable to smooth out the temperature distribution in the target material. One approach for achieving this effect is to coat the entrance end of the beam- 
stop with pyrolytic carbon with the high thermal conductivity direction oriented parallel to the face of the beam-stop. Comparisons of the radial and longitudinal temperature profiles with and without pyrolytic carbon show that pyrolytic carbon is effective in smoothing out the temperature distribution in target systems such as $\mathrm{Al}_{2} \mathrm{O}_{3} / \mathrm{Ir} / \mathrm{RVCF}$ and $\mathrm{UC}_{2} / \mathrm{Ir} / \mathrm{RCVF}$. This approach will be studied further.

\section{DIFFUSION RELEASE}

Fast escape of nuclear reaction products from the target material is very important in order to obtain a high yield of radioactive species of interest. The speed of release is dependent on the diffusion constant, the target temperature, and the target thickness through which the radioactive particles must pass prior to arriving at the surface of the target material. The diffusion of radioactive species from powder or foil targets has been extensively studied $[9,10]$ and the diffusion constants in several target materials have been experimentally measured by the use of ion implantation technique [11]. Under the assumption that surface adsorption is fast compared to the mean diffusion time within the target material, the diffusion problem is simplified and a closed analytical expression for the diffusion yield can be derived from the Fick's laws as shown in the following. For the release of radioactive isotopes of decay constant $\lambda$, the time-dependent diffusion equation, modified to include the rate of production $S$ and the rate of decay loss $E$, can be expressed in a Cartesian coordinate representation as follows: 


$$
\frac{\partial n}{\partial t}=D\left(\frac{\partial^{2} n}{\partial x^{2}}+\frac{\partial^{2} n}{\partial y^{2}}+\frac{\partial^{2} n}{z^{2}}\right)+S(x, y, z, t)-E(x, y, z, t)
$$

where $n$ is the concentration of the diffusing substance; $D$ is the diffusion coefficient, assumed to be independent of concentration. For an uniform distribution of radioactive species produced with a primary ion beam of intensity $I$ and charge $Z$, the production rate $S$ is given by

$$
S(x, t)=\frac{\sigma n I L}{Z e V}
$$

where $e$ is the charge on the electron, $n$ is the density of interaction nuclei, $I$ is the intensity of the primary ion beam, $L$ is the length of the target material, $\sigma$ is the cross section for production of the species of interest, and $V$ is the volume over which the species are distributed. The decay loss $E$ is identically equal to

$$
E(x, t)=n \lambda \quad \text { where } \lambda=0.693 / \tau_{\mathrm{t} / 2}
$$

for radioactive species with half-life $\tau_{1 / 2}$.

The rate of diffusion release from a target material can be calculated by solving the appropriate form of Eq. 1. Diffusion in composite RVCF targets coated with selected target materials can be modeled by solving the one-dimensional equation for a planar geometry target. For an initially homogeneous distribution of nuclei in an infinite planar target of thickness $l$, assuming that the species do not diffuse into the carbon substrate but are reflected at the boundary, the fractional release $f(t)$ is given by 


$$
f(t)=1-\frac{2}{l^{2}} \sum_{n=0}^{\infty} \frac{\exp \left\{-\mu_{n} D t\right\}}{\mu_{n}}
$$

where $\mu_{n}=(n+1 / 2)^{2} \pi^{2} n^{2}$. And the total diffusion release rate per unit surface area follows

$$
R(t)=\frac{2 S}{l} \sum_{n=0}^{\infty} \frac{1-\exp \left\{-\left(\mu_{n}+\frac{\lambda}{D}\right) D t\right\}}{\mu_{n}+\frac{\lambda}{D}} .
$$

The calculated fractional release from the low-density composite targets composed of 12 $\mu \mathrm{m} \mathrm{UC} \mathrm{UC}_{2}$ coated on $\mathrm{RVCF}$ is shown in Fig. 5 for different diffusion coefficients. As one can see, it is essential to have the diffusion coefficient larger than $10^{-9} \mathrm{~cm}^{2} / \mathrm{s}$ in order to reduce the decay losses of short-lived radioactive species during the diffusion through the target material. The estimated diffusion release rate of ${ }^{132} \mathrm{Sn}$ from the $\mathrm{UC}_{2} / \mathrm{RVCF}$ target is plotted in Fig. 6 for 60 $\mathrm{MeV}, 200 \mathrm{MeV}$ and $1 \mathrm{GeV}$ protons, respectively.

The fractional release $f(t)$ of nuclei uniformly distributed within a fibrous metal-oxide target material of radius $r$, can be obtained by solving the Eq. 1 in cylindrical geometry

$$
f(t)=1-\frac{4}{r^{2}} \sum_{n=1}^{\infty} \frac{\exp \left\{-\alpha_{n}^{2} D t\right\}}{\alpha_{n}^{2}}
$$

where $\alpha_{n}$ s are the positive roots of Bessel functions of the first kind of zero order, $J_{0}\left(\alpha_{n} r\right)=0$. The total release rate per unit length of the fiber material then becomes 


$$
R(t)=4 \pi S \sum_{n=1}^{\infty} \frac{1-\exp \left\{-\left(\alpha_{n}^{2}+\frac{\lambda}{D}\right) D t\right\}}{\alpha_{n}^{2}+\frac{\lambda}{D}} .
$$

Figure 7 shows the fractional release of fluorine from $6 \mu \mathrm{m}$ diameter $\mathrm{Al}_{2} \mathrm{O}_{3}$ fibers, assuming the diffusion coefficient $\mathrm{D}=10^{-10} \mathrm{~cm}^{2} / \mathrm{s}$. The total ${ }^{17} \mathrm{~F}$ and ${ }^{18} \mathrm{~F}$ release rates from the $\mathrm{Al}_{2} \mathrm{O}_{3}$ fibrous targets are presented in Fig. 8. Although the diffusion release has been simulated in the framework of a simple diffusion model, the results show that these low-density fibrous target matrices can offer fast diffusion release of short-lived radioactive species such as ${ }^{132} \mathrm{Sn}$ and ${ }^{17} \mathrm{~F}$ to meet the intensity requirements for research programs at the HRIBF.

\section{ACKNOWLEDGEMENTS}

Research at the Oak Ridge National Laboratory is supported by the U.S. Department of Energy under contract DE-AC05-96OR22464 with Lockheed Martin Energy Research Corp.

\section{REFERENCES}

1. G. D. Alton, Nucl. Instr. and Meth. A 382, 207 (1996).

2. R. Kirchner and E. Roeckl, Nucl. Instr. and Meth. 133, 187 (1976).

3. H. K. Carter, J. Kormicki, D. W. Stracener, J. B. Breitenbach, J. C. Blackmon, M. S. Smith, and D. W. Bardayan, Nucl. Instr. and Meth. B 126, 166 (1997).

4. R. F. Welton, et al., to be published

5. Private communication with D. W. Stracener, Oak Ridge National Laboratory, Oak Ridge, TN.

6. G. D. Alton, CP392, Appl. of Accel. in Res. and Ind., Edited by J. L. Duggan and I. L. Morgan, AIP Press, New York, 1997, p. 429.

7. SRIM - The Stopping and Range of Ions in Matter, J. F. Ziegler, IBM Research, Yorktown Heights, New York 10598, USA. 
8. ANSYS is a finite element computer code designed to solve thermal transport and radiation problems; the code is a product of Swanson Analysis Systems, Inc., Houston, PA 15342-0065.

9. H. L. Ravn, L. C. Carraz, J. Denimal, E. Kugler, M. Skarestad, S. Sundell, and L. Westgaard, Nucl. Instr. and Meth. 139, 267 (1976)

10. R. Kirchner, Nucl. Instr. and Meth. B 70, 186 (1992).

11. G. D. Alton and J. Dellwo, Nucl. Instr. and Meth. A 382, 225 (1996). 


\section{Figure Captions}

Fig. 1. The vapor pressures of $\mathrm{Al}_{2} \mathrm{O}_{3}, \mathrm{ZrO}_{2}, \mathrm{HfO}_{2}$, and $\mathrm{Y}_{2} \mathrm{O}_{3}$ calculated using the ThermoCalc code. The maximum operating temperature of these metal oxide targets is set by the vapor pressure limitation of the ion source system that must be below $2 \times 10^{-4}$ torr for the CERN-type electron-beam-plasma ion source presently used at the HRIBF.

Fig. 2. ORNL-DWG 95-10133. Schematic drawing of a removable/insertable composite target/heat-sink system showing the components which make up the system now under design at the HRIBF for use in RIB generation. The target material may be particulate, plated onto component target support disks or fibers.

Fig. 3. Axial target temperature versus beam power in a $2.5-\mathrm{cm}$ long fibrous $\mathrm{Al}_{2} \mathrm{O}_{3}$ target spiral rolled with $25-\mu \mathrm{m}$ thick Ir, irradiated by $20 \mathrm{MeV}$ deuterons.

Fig. 4. Maximum target temperature versus beam power in a $2.5-\mathrm{cm}$ long fibrous $\mathrm{Al}_{2} \mathrm{O}_{3}$ target irradiated by $20 \mathrm{MeV}$ deuterons: without cooling means; " radial cooling by the use of $8 \mathrm{Mo}$ mesh disks, ion beam diameter $=8 \mathrm{~mm}$; and $\triangleleft$ radial cooling with ion beam diameter $=16 \mathrm{~mm}$, respectively.

Fig. 5. The calculated fractional release from the low-density composite targets composed of 12 $\mu \mathrm{m} \mathrm{UC}_{2}$ coated on RVCF for different diffusion coefficients.

Fig. 6. The estimated diffusion release rate of ${ }^{132} \mathrm{Sn}$ from $\mathrm{UC}_{2} / \mathrm{RVCF}$ targets irradiated with $1 \mu \mathrm{A}, 60 \mathrm{MeV}, 200 \mathrm{MeV}$ and $1 \mathrm{GeV}$ protons, respectively. Diffusion coefficient $\mathrm{D}=8 \times 10^{-8}$ $\mathrm{cm}^{2} / \mathrm{s}$.

Fig. 7. Fractional release of fluorine from $6-\mu \mathrm{m}$ diameter $\mathrm{Al}_{2} \mathrm{O}_{3}$ fibrous targets. Diffusion coefficient $\mathrm{D}=10^{-10} \mathrm{~cm}^{2} / \mathrm{s}$.

Fig. 8. The estimated diffusion release rate of ${ }^{17} \mathrm{~F}$ and ${ }^{18} \mathrm{~F}$ from the $\mathrm{Al}_{2} \mathrm{O}_{3}$ fibrous targets. Diffusion coefficient $\mathrm{D}=10^{-10} \mathrm{~cm}^{2} / \mathrm{s}$. 


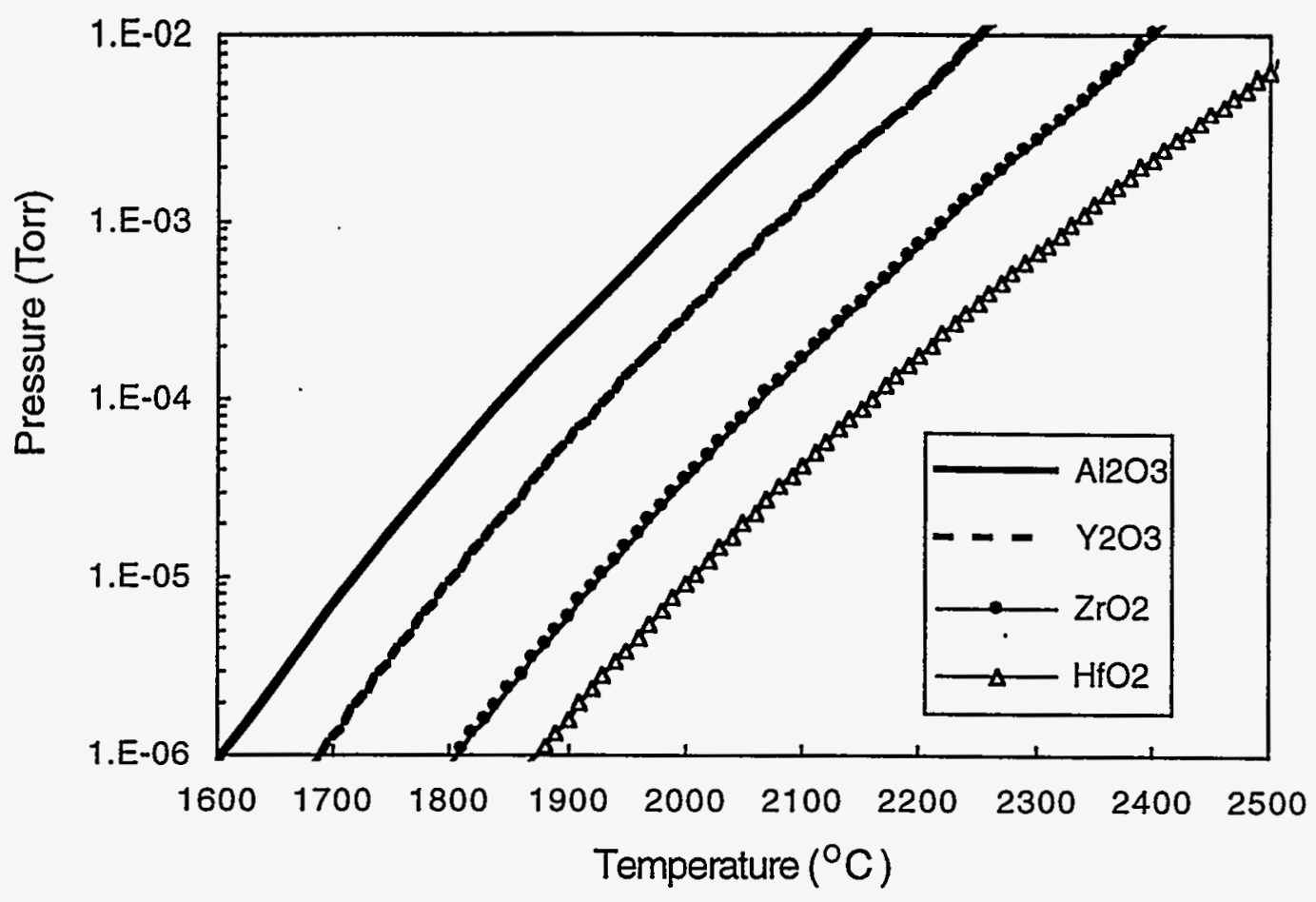

Fig. 1. 


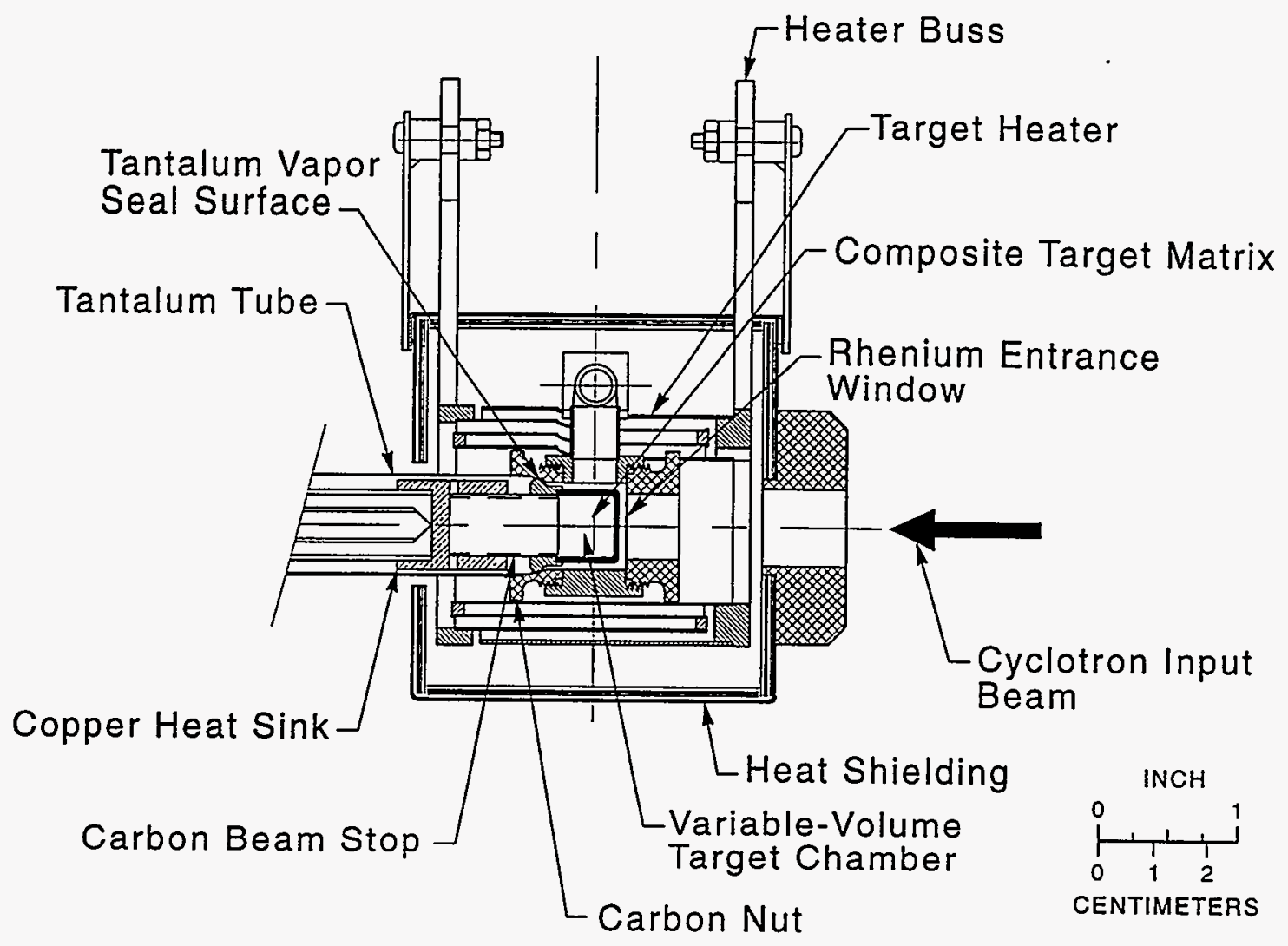

Fig. 2. 


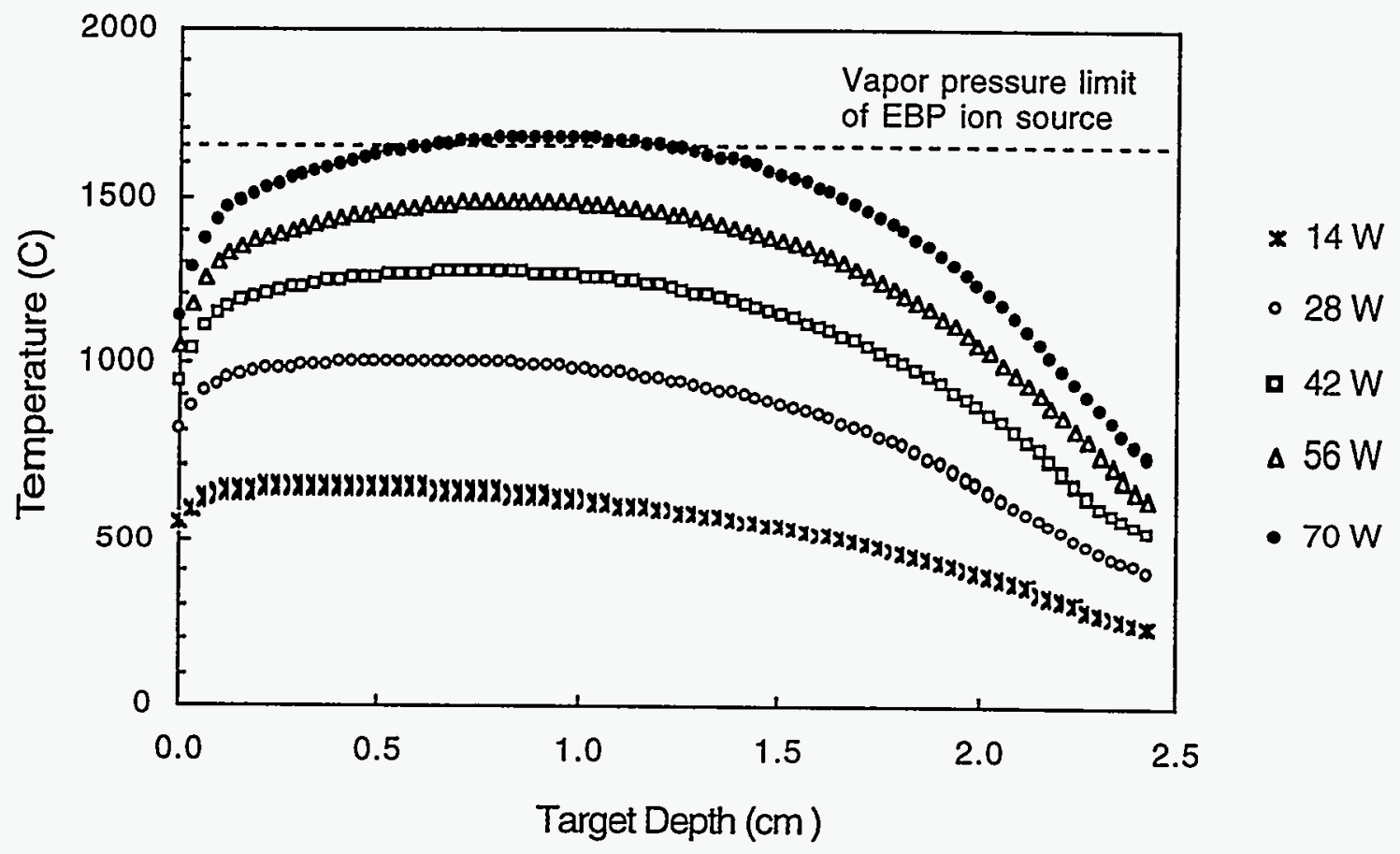

Fig. 3. 


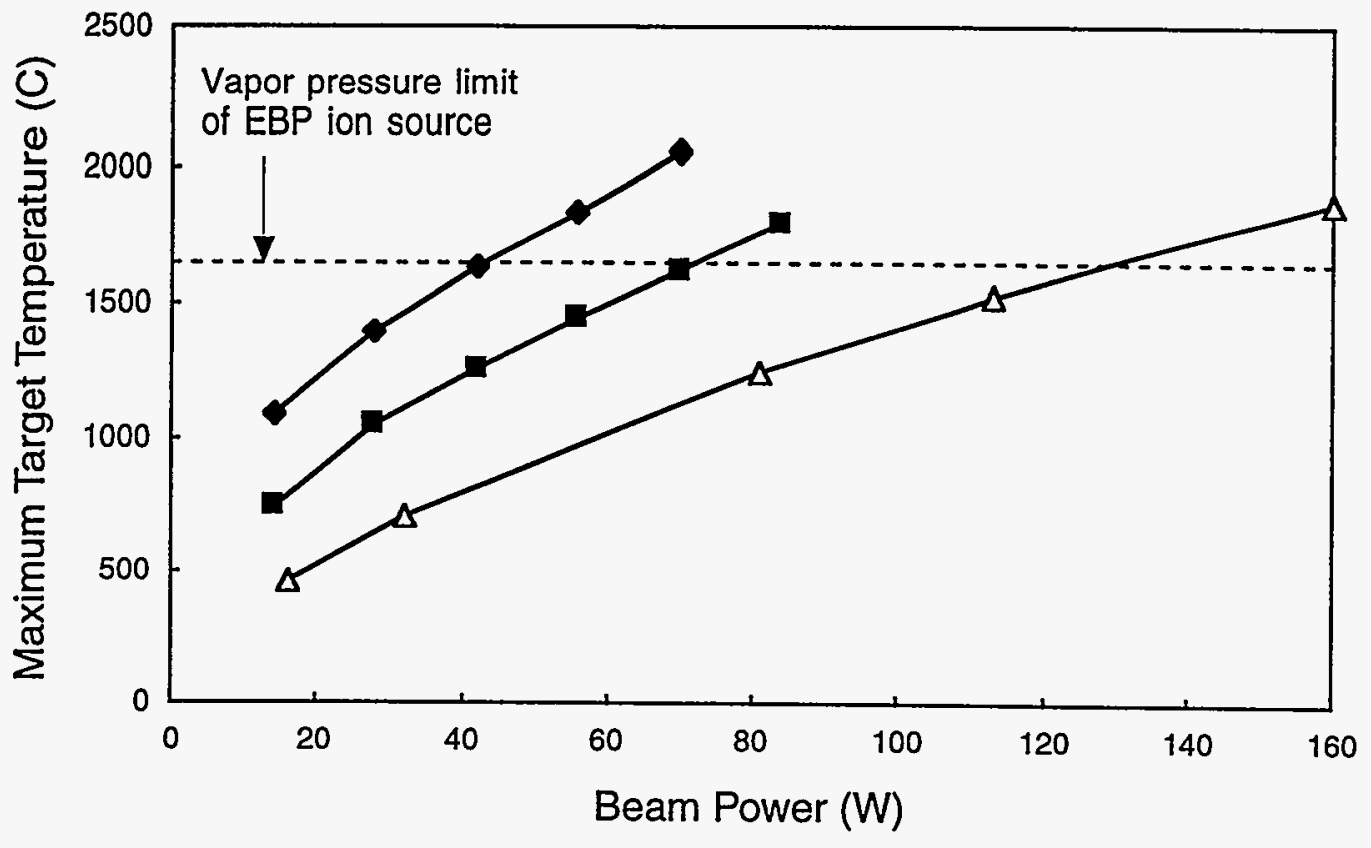

Fig. 4. 


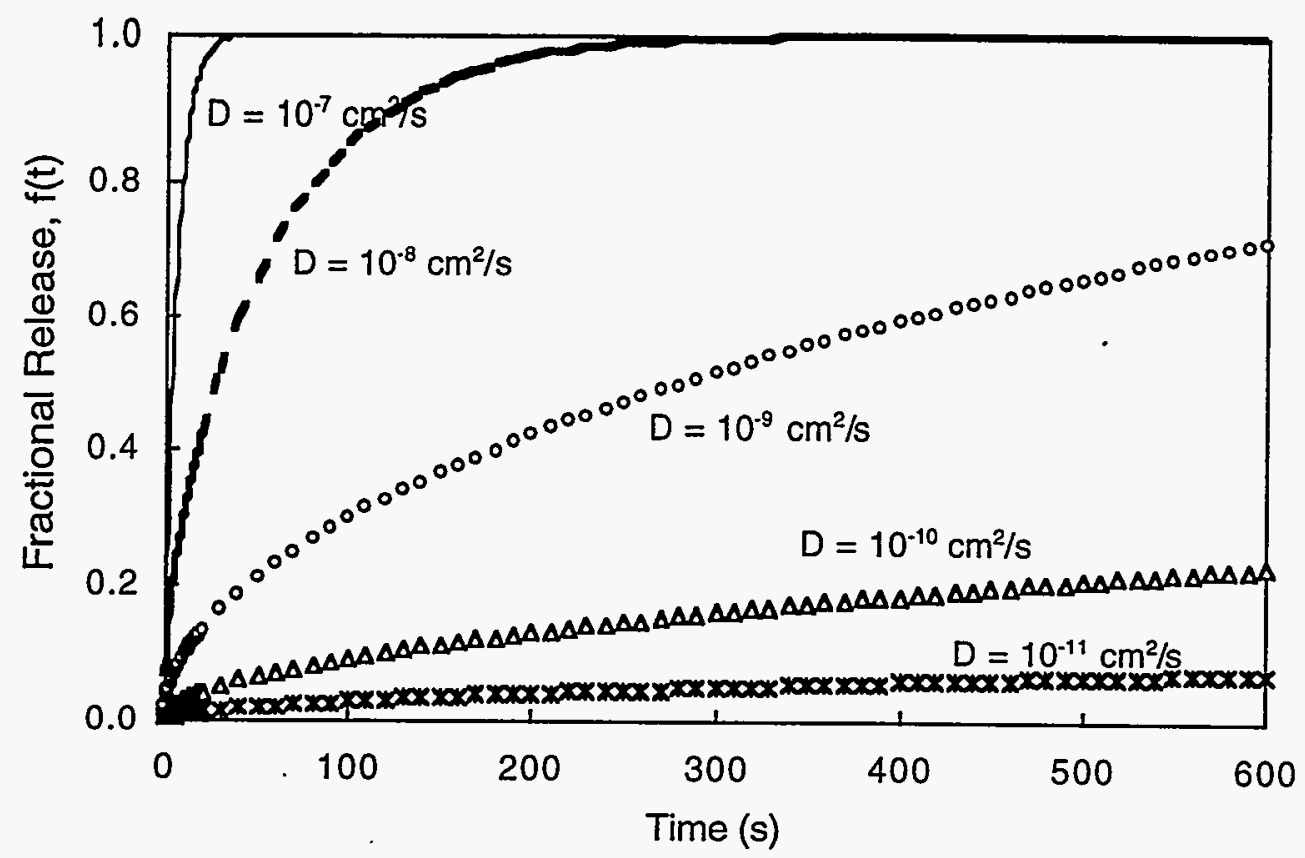

Fig. 5. 


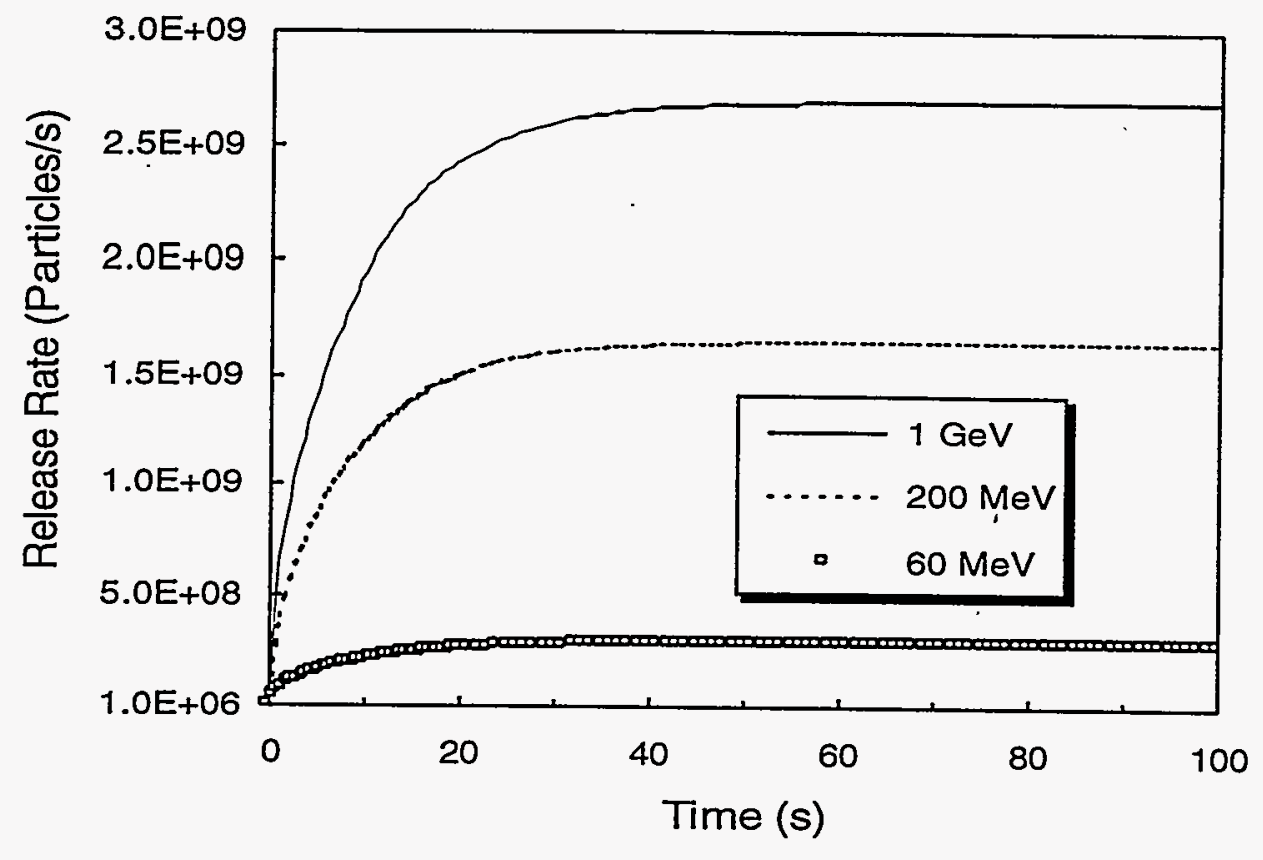

Fig. 6 . 


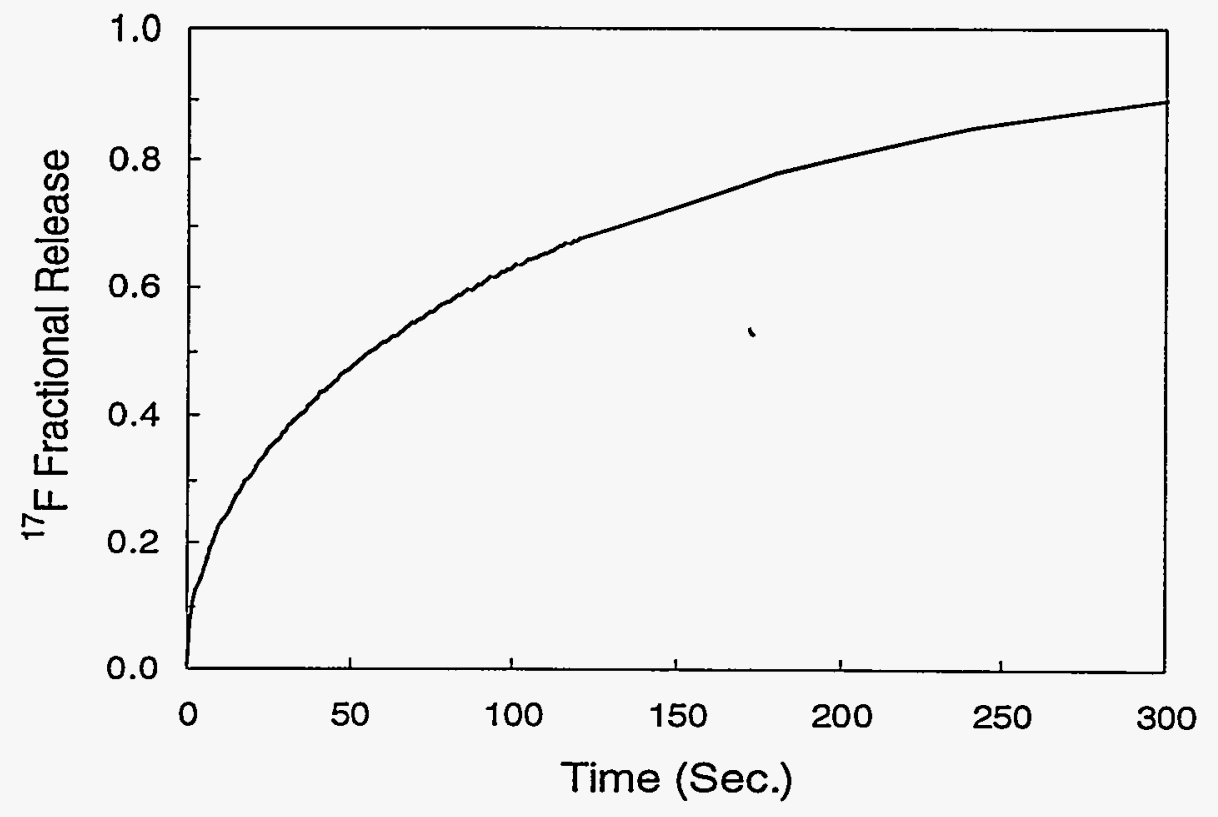

Fig. 7 


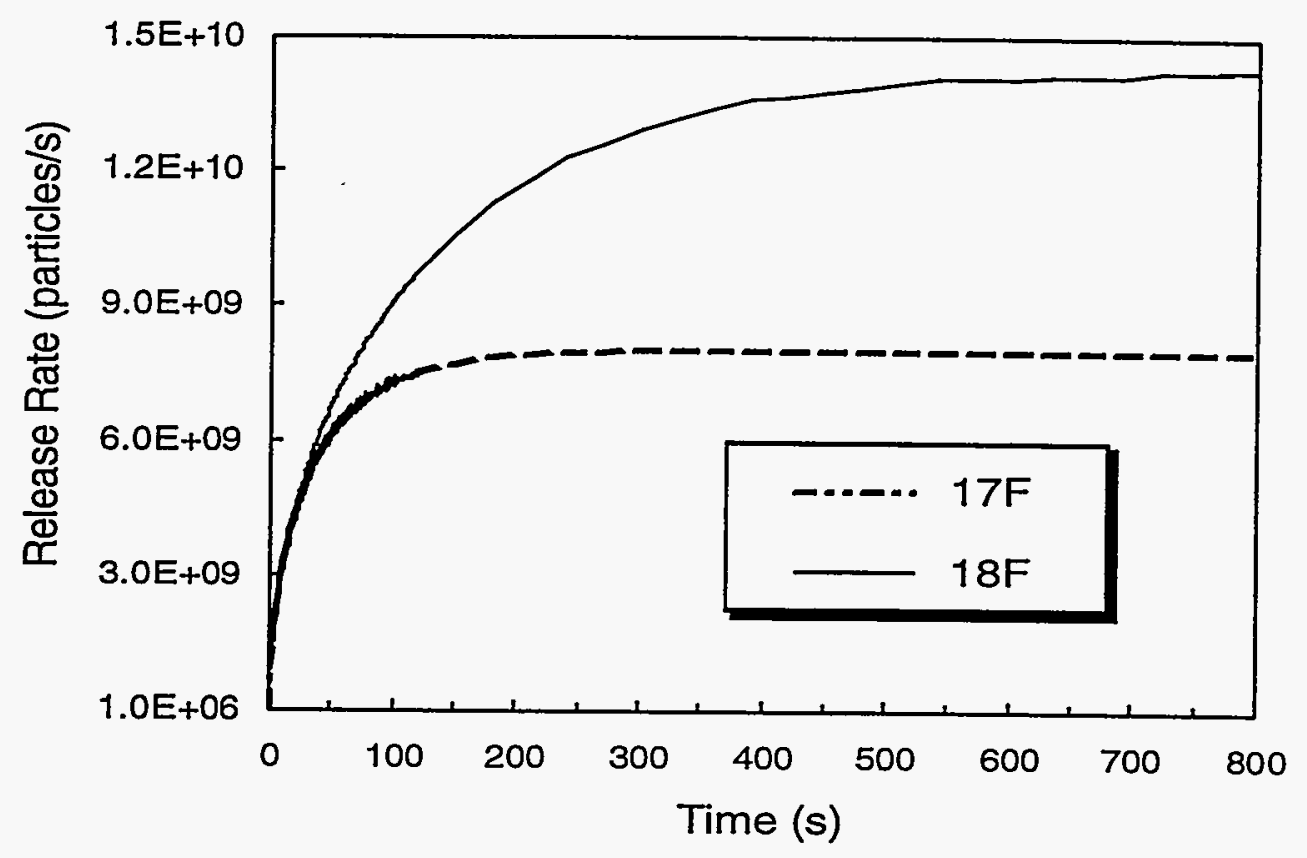

Fig. 8. 